Paper-An Eight-Layer Model for Mathematical Cognition

\title{
An Eight-Layer Model for Mathematical Cognition
}

\author{
https://doi.org/10.3991/ijet.v13i10.8633 \\ Marios A. Pappas $\left({ }^{\bowtie}\right)$ \\ National and Kapodistrian University of Athens, Greece \\ mpappas @ppp.uoa.gr \\ Athanasios S. Drigas \\ National Center for Scientific Research 'Demokritos', Athens, Greece \\ Fotini Polychroni \\ National and Kapodistrian University of Athens, Greece
}

\begin{abstract}
In recent years, more and more researchers have been investigating mathematical knowledge, as well as the cognitive skills that seem to be related to the improvement of mathematical thinking, numerical skills, mathematical logic and problem solving techniques. In this paper, we present the cognitive processes that are related to mathematical performance, such as working memory, anxiety, attention, spatial cognition, executive function and phonological awareness. In addition, we refer to metacognitive skills and their role in controlling and regulating cognitive processes, in order to improve mathematical performance. Finally, we present a new taxonomy of mathematical skills, the pyramid of mathematical cognition, as well as their gradual development through the appropriate cognitive and metacognitive mechanisms.
\end{abstract}

Keywords-Cognition, Knowledge Management, Mathematical Knowledge, Taxonomy, Metacognition, Behaviour Modelling.

\section{Introduction}

Solving strategies for most mathematical problems begin with setting a goal, or sub-goals if necessary, and require transformation of a given state into an equation, in order to calculate the unknown value. Individuals should activate their cognitive mechanisms, as well as their previous experience, in order to recall learning strategies from problems of the same category [1]. Problem solving requires in addition to the understanding of mathematical operators, formulas and theorems, the utilization of cognitive processes, such as working memory, attention, long-term memory retrieval and spatial abilities [2]. Deficits of students with mathematical learning disabilities or low achievement focus on retrieving mathematical facts they have learned, while problem solving [3]. In an attempt to analyze the cognitive processes that evolve in the mind of an individual during problem solving, we should take into account the kind of each mathematical problem as well as the level of difficulty. They may be routine problems which are aimed at understanding of the pupil on an axiom or a 
theorem, complex problems that require the recording of data and combination of theorems and methodologies, or even problems with high difficulty, in which the utilization of known theorems and formulas does not guarantee the solution, but is required creativity and critical thinking. Strengthening of metacognitive skills such as self-regulation and self-control could greatly contribute to improving problem solving skills [4].

Knowledge of Mathematics is not something static, such as dealing with numbers, arithmetic operations and abstract structures. Instead it is a dynamic process that includes the creation, the exploration, as well as the connection of mathematical models [5]. For this reason, exploration of the way in which mathematical knowledge is acquired step by step, as well as research for cognitive parameters of mathematical knowledge are considered as remarkable topics. Cognitive Informatics is an emerging discipline, which links information processing mechanisms and processes of human knowledge and natural science with informatics and computing science [6]. The Cognitive Psychology domain converge to the domain of Information and Communication Technologies (ICTs) [7]. Indicative of the influences of these two fields, is the structure of various behavioural and psychological models such as Bloom's taxonomy of reasoning skills [8], SOLO Taxonomy of learning outcomes [9] and Wisdom Hierarchy [10], compared to the conceptual model for Telecommunications and Computer Networks OSI model [11] as well as the TCP Internet Protocol (IP) suite [12]. This paper presents the construction of a cognitive-based new theory for Mathematical Knowledge, a layered reference model [13] in an attempt to analyze the structure, the functional mechanisms, the cognitive processes as well as the metacognitive skills of mathematical knowledge. This theory can be used as a useful tool for educators, regarding the structure of mathematical knowledge and how it is acquired.

\section{Aims and Methodology}

This research does not seek to simply represent what has been written for mathematical knowledge as a typical review [14]. Instead, our research is based on the exploratory literature of the most popular published articles and book chapters in the field of Mathematical Knowledge, as we summarize what developmentalists, psychologists and educators believe about Mathematical Knowledge and Cognition [15] in order to investigate:

1. The progressive development of mathematical skills (numerosity, approximation of quantity, arithmetic operations, algebraic structure, geometry, problem solving, reasoning, etc)

2. The cognitive factors that could affect or predict mathematical performance.

3. What is the role of metacognition as well as of the executive function on the development of mathematical skills.

Based on the findings arising from the investigation of the objectives above, we propose a new taxonomy of mathematical skills, forming the Pyramid of Mathematical Cognition, a cumulative hierarchical framework [16] of eight layers, indicating at 
the same time the cognitive procedures, as well as the metacognitive skills required for the individual to 'ascend' to the next layer of the pyramid.

\section{$3 \quad$ Research Findings}

\subsection{Cognitive Factors of Mathematical Performance}

Engaging in Mathematics and particularly in tasks such as performing arithmetic operations, solving problems with appropriate strategies, interpreting graphs or charts, etc., is a complex process that assumes the proper functioning as well as the coordination of the cognitive functions of the brain. Harvey (2010) proposed an organization of numerical cognition. According to his approach, any mathematical task starts from a stimulus (digit or spoken number) received by the sensory systems (visual or auditory) then move to the object recognition systems (categorical, quantity, visual number form, visual word form, linguistic word recognition), then to the semantic systems (quantity or linguistic number) and finally to the mathematical systems (physical mathematical rules, abstract mathematical operations) [17].

Working Memory, defined as the ability for temporary storage and handling data during a task [18] is considered as an important factor of mathematical performance. Visual Working Memory as well as symbolic number sense are indicative measures of the subsequent mathematical evolution of 1st grade students. For this reason, symbolic numerical skills should be considered as more crucial for students' mathematical performance, than non-symbolic skills [19]. Swanson and Fung (2016) accomplished a study in order to evaluate the relationship between the Working Memory components (central executive, phonological loop, visual-spatial sketchpad) and word problem solving accuracy in elementary school students. According to the results the executive component seems to be highly connected to various mediating variables such as reading, calculation, representation, magnitude comparison, inhibition and naming speed. Generally Working Memory seems to be significantly correlated with the strength of problem solving skills [20].

Visual Sustained Attention, defined as the ability to maintain the focus of attention to specific objects [21], seems to be highly correlated with mathematical achievement and especially Arabic numeral recognition and comparison, number line sense, simple calculations, counting and multiplication tables [22]. Arithmetic problem solving tasks that require addition or subtraction, are correlated to the right and left attention shifts respectively [23].

Test anxiety is considered as an inhibitory factor of mathematical performance, with greater impact on students with lower Working Memory capacity. Test anxiety reduces Working Memory resources as well as attention control, which are both significantly important while problem solving [24]. Despite the fact that anxiety can cause a decrease in performance on students with low working memory capacity, there are indicators that students with high working memory capacity may benefit from the anxiety and get higher scores on math tests [25]. 
The meaning of numbers is spatially coded for most people, as number magnitude is represented on a left-to-right oriented mental number line [26]. Spatial ability seems to be correlated with the capacity of visualization of mathematical concepts, a process that can contribute to the development of mathematical concepts [27]. Duffy et al (2016) examined the role of spatial cognition in problem solving. In order to measure spatial aptitude, researchers used Mental Cutting Test, a paper and pencil test in which students are expected to mentally cut 3D geometric figures and state which will be the cut face formed. The results of the study revealed that there is a significant correlation $(\mathrm{r}=.79)$ between spatial test and math test (word problems) scores [28]. Furthermore, Cheng \& Mix (2014) showed that there is positive effect of spatial training through mental rotation practice on 6- to 8-year olds' mathematical ability. During mental rotation practice, children were given two parts of a shape and thus they were asked to indicate the original shape among different given shapes [29].

Phonological awareness is correlated with reading ability, but seems that it can't be considered as a predictor of mathematical ability [30]. A 3-year study examined the impact of phonological awareness on quantity-number competencies and mathematical achievement of third grade students. According to the results, phonological awareness facilitates the acquisition of quantity-number competencies skills, but it is not sufficient prerequisite for the development of mathematical skills [31].

\subsection{The Role of Executive Function \& Metacognition}

Executive function is a set of processes that are responsible for the control, management and coordination of cognitive skills [32]. The main executive function skills that have been associated with developmental mathematical proficiency are inhibition, the ability not to be distracted from irrelevant information, shifting, the ability to switch between different tasks and updating, defined as the ability to monitor and handle stored information [33]. The ability of switching between tasks or strategies, as well as the low amount of interference from irrelevant information could be considered as indicators of high mathematical skills [34]. Verdine et al (2014) investigated the contribution of executive function to preschool mathematics achievement [35]. Researchers used the Tap Test [36] and the Flexible Item Selection Task [37] in order to assess participants' inhibitory control and cognitive flexibility respectively. Based on the results researchers claimed that both skills have direct correlation with students' mathematical skills and they can party predict math performance during early school years.

There is a major distinction between mathematical computation and problem solving, as in contrast with computation problems which are set up for solution, word problems provide linguistic information, linking word identification skills with problem solving skills [38]. Students can improve their problem solving strategies, their self-regulation and generally their mathematical performance, through training their metacognitive skills from early school age to early adolescence [39]. Furthermore, metacognitive skills are required during problem solving, in order for individuals to monitor their performance, estimate the solution and recall personal experiences from similar situations. The concept of metacognition could be defined as the knowledge of 
the individual for his/her own cognitive abilities. Monitoring, or the ability of individuals to distinguish what they know and what they don't, is considered as the fundamental component of metacognition. After conquering monitoring of knowledge, individuals can move on to more advanced metacognitive procedures, such as selecting solving strategies, evaluating learning and planning [40]. Metacognition is directly related to self-regulation, i.e. control and coordination of cognitive functions [41], a necessary process during problem solving. Highly important for self-regulation are metacognitive and emotional experiences of the individual. The more word problems a student is dealing with, the more experiences he gets. Özsoy, G. (2011) investigated the relationship between metacognition and mathematics achievement on fifth-grade students. Metacognitive Skills and Knowledge Assessment test was used in order to measure participants' metacognitive parameters (declarative, procedural and conditional knowledge, prediction, planning, monitoring and evaluation skills). The results revealed a strong positive relationship between metacognition and mathematics achievement [42].

Metacognitive skills of the individual could be improved through intervention and appropriate guidance from the tutor, in terms of the cognitive processes and the development of appropriate strategies. Metacognitive knowledge about problem solving strategies could benefit even elementary (second grade) math students [43]. This presupposes that the tutor has explained to the students when and why each solving strategy is useful, giving them the opportunity to evaluate and choose the appropriate one for a given problem. Pennequin et al (2010) examined how training of metacognition could enhance cognitive and problem solving skills of third grade elementary school students. The developing-metacognitive-skills sessions were targeted on word problem representation, developing strategies for problem-solving, problem interpretation using key-words and identification of mathematical expressions. According to the results of the study, metacognitive training (five 1-hour training sessions) could increase metacognitive knowledge of low achieving students, but not on normal achievers [44]. Mevarech \& Fidkin (2006) evaluated the effect of the 'IMPROVE' method on the mathematical reasoning and metacognition of pre-college students who studied the course 'mathematical functions'. According to this method, students of the experimental group should answer a metacognitive knowledge questionnaire (containing comprehension, connection, strategic and reflection questions) during solving optimization problems. The method had a significantly positive impact on post-test scores on mathematics achievement, as well as on general metacognition [45].

\section{Development of Mathematical Cognition: The Eight-Layer Model}

Geary (2000) named the biologically primary mathematical abilities (infancy and preschool) as numerosity, ordinality, counting and simple arithmetic. As secondary mathematical abilities) primary and secondary schooling) he named master of counting, number transcoding, computations and word problem solving [46]. The learning process should target to the development of the cognitive functions which can 
strengthen associations between stimuli (given word problems) and students' responses [47]. Tasks that build on students' prior knowledge assigned for an approximate amount of time, as well as sustained pressure for explanation and meaning, are considered as factors, which could influence students to engage with high-level mathematical processes [48]. In this chapter, we analyze the development of arithmetic skills, mental arithmetic, goal oriented strategy choice skills and generally the development of mathematical cognition, recording the different levels of acquisition.

\subsection{Sensory Arithmetic}

Students are able to do non-symbolic number comparison (dot comparison) as well as symbolic number comparison, connecting the Arabic numerals to the corresponding numerical quantity. Students are familiar to numeracy related activities like counting, recognizing digits or home activities such as playing with dice, which will improve their performance in mathematical tasks [49]. Most children learn how to enumerate small sets during preschool and kindergarten [50] while approximate number sense could be developed even on newborn infants [51]. Approximate numerical abilities, such as mental arithmetic (comparison or addition) on non-symbolic arrays of objects are correlated to symbolic mathematical abilities, as cognitive processes like visual attention and working memory are considered to be involved in both symbolic and non-symbolic tasks [52]. They can read, write and order natural numbers (creating a mental number line). Gifted children tend to use the linear representation for number line placements, while their classmates usually use the logarithmic representation [53]. They are also able to recognize basic geometric figures in 2 or 3 dimensions. Finally, they can recognize and describe numerical and geometric patterns, they can identify and describe numerical or geometric patterns and they have developed spatial orientation skills (up-down-right-left).

\subsection{Basic Arithmetic}

During the very first grades of school, children come into contact with arithmetic and mathematics generally. They learn to read and write initially 2-digit and then 3digit numbers, recognizing the numerical quantity that each one represents. They know how to do basic arithmetic operations like addition, subtraction, multiplication and division, as well as the basic arithmetic properties (commutative property, associative property, etc.). At the beginning, students are based on counting strategies in order to do simple arithmetic operations, the results of which are stored in memory, enhancing thus direct retrieval [54]. Finally, students are able to recognize and draw geometric figures like lines and line segments, as well as to understand the concept of symmetry about an axis.

\subsection{Elementary Mathematical Thinking}

Students have the ability to understand fundamental mathematical concepts such as integers, decimals, fractions, positive-negative, lines, etc. They are able to recall 
number properties, rules and theorems in order to solve basic mathematical tasks, provided that appropriate examples have been taught. They can also make logical conclusions as they understand compound statements of the form 'if $p$ then q'. However, sometimes students may give a false impression that they have understood, while they simply memorize the solving methodology of a specific task, and thus fail to solve similar exercises with different structure or with data given in a different way than usually. They are used to solve practice problems of a specific type each type that they have just learned, but they face difficulties when they are asked to solve problems of various types, especially when they require retrieval of prior knowledge [55].

\subsection{Intermediate Mathematical Thinking}

Students understand important mathematical concepts, retrieve mathematical techniques and methodologies in order to solve simple math problems. They are able to translate a given math problem, seeking what is wanted, naming variables, utilizing given data and forming equations. Although they are not aware of the different problem solving approaches they could follow to reach an efficient solution for a given problem, and thus they always prefer an algebraic approach [56]. They have the ability to read and interpret propositions, graphs, diagrams or other mathematical descriptions as well as the ability to do the reverse process, i.e. to represent a mathematical idea or a verbally formulated math problem using mathematical symbols, graphical depictions or geometric forms.

\subsection{Coherent Mathematical Thinking}

Students have now deeply understood important math concepts and are not content with memorizing rules and theorems. They are able to develop their own strategy in order to solve complex math problems, analyzing the problem into sub-problems and combining techniques and theories that have been taught in the past. They have high levels of self-efficacy and thus they attempt more challenging problems [57]. They start to show particular interest in mathematics, not only as regards their obligations in school, but also outside of it in order to investigate more and answer some of their own questions. They are looking to find how different mathematical topics are connected to each other, as well as how mathematics can be applied to physics, economics or other sciences.

\subsection{Advanced Mathematical Thinking}

Students with advanced mathematical thinking have developed multiple mathematical skills and are now able to solve complex math problems, applying high techniques and seeking the optimal solution. When problem solving, their solutions not only look correct, but also are accompanied by appropriate justifications, showing proof-like procedures and logical evidence [58]. They are able to understand abstract mathematical concepts and desire deeper knowledge and understanding, seeking ori- 
gins of mathematical concepts, proofs of theorems, as well as applications of math concepts in real life. They can also take advantage of inductive logic in order to generalize math concepts and generate math concepts.

\subsection{Mathematical Wisdom}

Individuals who have reached mathematical wisdom have mastered most of the mathematical knowledge and could be considered as experts in the field of Mathematics. Experts have the ability to understand unfamiliar mathematical concepts or phenomena, combining and synthesizing their prior knowledge [59]. Cognitive flexibility is considered as a key factor that could contribute so that an individual can become expert in mathematics [60]. The term cognitive flexibility is used to describe the mental ability of an individual to switch between different thoughts, or to think about different concepts simultaneously [61].

\subsection{Mathematical Transcendence}

We could define mathematical transcendence as the ability to explore hidden patterns, which will help us understand the world better [62]. Individuals who achieve transcendence are able to go beyond the existing knowledge, perceiving the connectedness of different representations as well as generalizing patterns [63]. Their need to search the unknown stems from intuitions, which can interfere with mathematical reasoning over logic [64].

As follows, we present the 8-layer model (pyramid) of Mathematical Cognition (figure 1) with respect to the mathematical skills and the cognitive development of the individual. For each layer of the pyramid, we define the cognitive skills that the individual should train, in order to conquer the mathematical skills of the corresponding layer and move to the next one, as well as the additional metacognitive skills required (table 1). As it is easily understood, as we move towards the top of the pyramid, we find increasingly smaller portion of the population with the corresponding skills. 


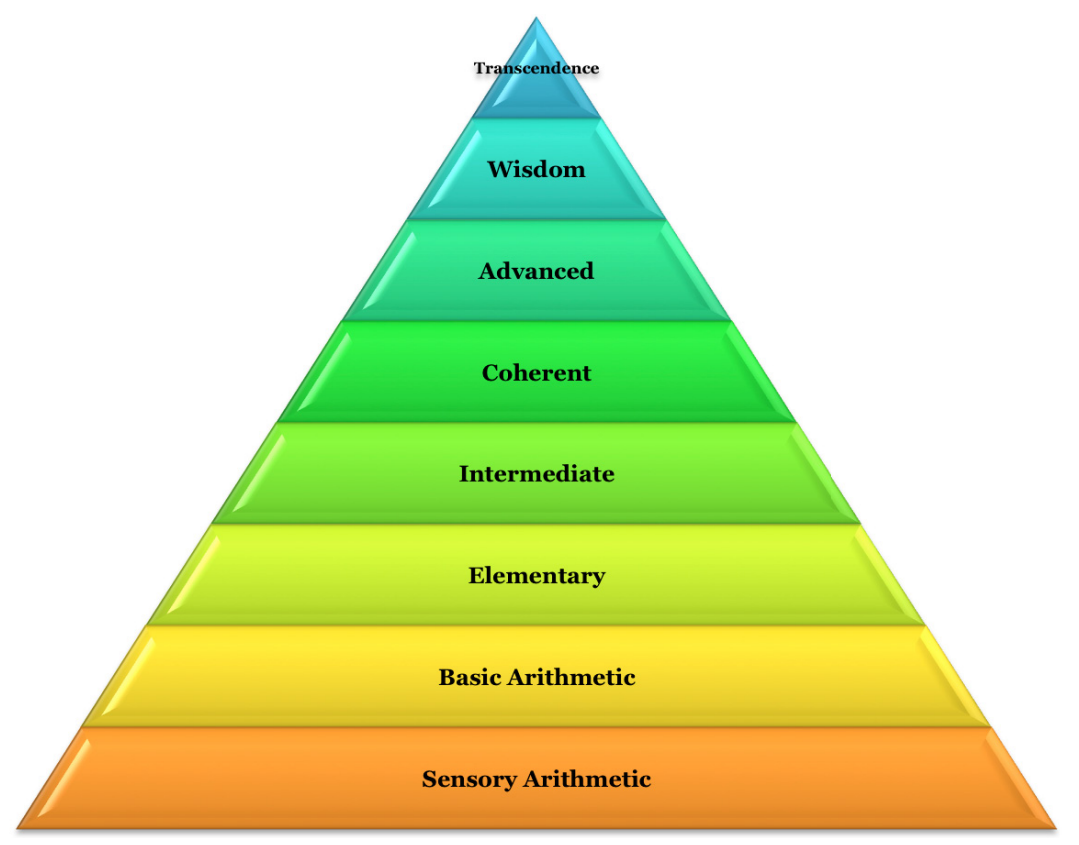

Fig. 1. The 8-layer model of Mathematical Cognition.

Table 1. Cognitive and Metacognitive procedures for each layer of the pyramid.

\begin{tabular}{|c|c|c|c|}
\hline Cognitive Layer & Mathematical Skills & Cognitive Procedures & Metacognitive Skills \\
\hline Sensory Arithmetic & $\begin{array}{l}\text { Quantity comparison, small } \\
\text { number comparison, enu- } \\
\text { meration of small sets, } \\
\text { approximate number sense }\end{array}$ & $\begin{array}{l}\text { Sensory encoding, Spatial } \\
\text { cognition }\end{array}$ & \multirow[t]{2}{*}{ Awareness } \\
\hline Basic Arithmetic & $\begin{array}{l}\text { Recognition of 2-digit and } \\
\text { 3-digit numbers, arithmetic } \\
\text { operations }\end{array}$ & $\begin{array}{l}\text { Synthesis \& structure of data, } \\
\text { Spatial cognition develop- } \\
\text { ment, sustained attention }\end{array}$ & \\
\hline $\begin{array}{l}\text { Elementary Mathemat- } \\
\text { ical Thinking }\end{array}$ & $\begin{array}{l}\text { Basic mathematical con- } \\
\text { cepts, rules \& theorems, } \\
\text { logical reasoning }\end{array}$ & $\begin{array}{l}\text { Recall of math concepts from } \\
\text { long-term memory }\end{array}$ & $\begin{array}{l}\text { Conditional } \\
\text { knowledge }\end{array}$ \\
\hline $\begin{array}{l}\text { Intermediate Mathe- } \\
\text { matical Thinking }\end{array}$ & $\begin{array}{l}\text { Solving algorithms and } \\
\text { strategies, data interpreta- } \\
\text { tion }\end{array}$ & Information processing & $\begin{array}{l}\text { Monitoring of skills, } \\
\text { abilities \& knowledge }\end{array}$ \\
\hline $\begin{array}{l}\text { Coherent Mathemati- } \\
\text { cal Thinking }\end{array}$ & $\begin{array}{l}\text { Combination of solving } \\
\text { techniques, applications of } \\
\text { mathematics in STEM }\end{array}$ & $\begin{array}{l}\text { Inter-connection of math } \\
\text { concepts, development of } \\
\text { new strategies }\end{array}$ & $\begin{array}{l}\text { Self-organization, } \\
\text { procedural knowledge, } \\
\text { Self-regulation }\end{array}$ \\
\hline $\begin{array}{l}\text { Advanced Mathemati- } \\
\text { cal Thinking }\end{array}$ & $\begin{array}{l}\text { Optimization of solution, } \\
\text { real life applications, } \\
\text { inductive logic, high level } \\
\text { reasoning }\end{array}$ & $\begin{array}{l}\text { Abstracting, Visualization of } \\
\text { math concepts }\end{array}$ & Shifting \& Updating \\
\hline Mathematical Wisdom & $\begin{array}{l}\text { Becoming expert of the } \\
\text { domain }\end{array}$ & Cognitive flexibility & $\begin{array}{l}\text { Perfecting, Abstract- } \\
\text { ing,Detaching }\end{array}$ \\
\hline $\begin{array}{l}\text { Mathematical Tran- } \\
\text { scendence }\end{array}$ & $\begin{array}{l}\text { Transcendental thinking, } \\
\text { pattern finding }\end{array}$ & $\begin{array}{l}\text { Extension of boundaries, } \\
\text { Creativity }\end{array}$ & Intuition, Planning \\
\hline
\end{tabular}




\section{$5 \quad$ Discussion \& Conclusions}

This paper shows that engaging in mathematics and problem solving is a sophisticated process that requires the proper development and collaboration of various cognitive functions [65]. Working Memory components and especially central executive, as the supervisory system, seem to be highly correlated with the development of numerical abilities, quantity comparison, naming speed and problem solving skills. Phonological awareness, known for its importance in reading, is also associated with the ability of the student to link a quantity with the corresponding Arabic digit. On the other hand, text anxiety could reduce attention control and thus negatively affect the effectiveness and the accuracy. Finally, spatial training on young elementary students seems to have positive effect on mathematical skills, as spatial cognition is correlated with mental number line sense, as well as with the general ability to visualize. Executive function, a set of mental skills for cognitive control (shifting, updating and inhibition), is responsible for the coordination of cognitive abilities and is considered as indicator of students' mathematical performance. In this paper we presented the pyramid of Mathematical Cognition, as an attempt to construct a new layer model, based on mechanisms and processes from Cognitive Psychology and Informatics. In order to move to a higher level of the pyramid of Mathematical Cognition, individuals should be properly guided through core-knowledge oriented education, so that they improve their metacognitive skills such as self-regulation, self-organization, awareness and consciousness. This new cognitive-based taxonomy of mathematical knowledge could be applied to the field of Education, e.g. for the formation of the curriculum in order to optimize learning outcomes, as well as for the assessment of students' mathematical skills.

\section{References}

[1] Sweller, J. (1988). Cognitive load during problem solving: Effects on learning. Cognitive science, 12(2), 257-285. https://doi.org/10.1207/s15516709 $\operatorname{cog} 1202 \quad 4$

[2] Geary, D. C., Hamson, C. O., \& Hoard, M. K. (2000). Numerical and arithmetical cognition: A longitudinal study of process and concept deficits in children with learning disability. Journal of experimental child psychology, 77(3), 236-263. https://doi.org/10.1006/jecp. 2000.2561

[3] Geary, D. C., Hoard, M. K., Nugent, L., \& Bailey, D. H. (2012). Mathematical cognition deficits in children with learning disabilities and persistent low achievement: A five-year prospective study. Journal of educational psychology, 104(1), 206. https://doi.org/10.1037/a0025398

[4] Lester, F. K. (1985). Methodological considerations in research on mathematical problemsolving instruction. Teaching and learning mathematical problem solving: Multiple research perspectives, 41-69.

[5] Farmer, W. M. (2006). Mathematical knowledge management. In Encyclopedia of Knowledge Management (pp. 599-604). IGI Global. https://doi.org/10.4018/978-1-59140$\underline{573-3 . \operatorname{ch} 078}$ 
[6] Wang, Y. (2007). The theoretical framework of cognitive informatics. International Journal of Cognitive Informatics and Natural Intelligence (IJCINI), 1(1), 1-27. https://doi.org/10.4018/jcini.2007010101

[7] Drigas, A., Koukianakis, L., \& Papagerasimou, Y. (2008). Psychology in the ICT era: Electronic psychology. Emerging Technologies and Information Systems for the Knowledge Society, 88-95. https://doi.org/10.1007/978-3-540-87781-3 10

[8] Bloom, B. S. (1956). Taxonomy of educational objectives. Vol. 1: Cognitive domain. New York: McKay, 20-24.

[9] Biggs, J. B., \& Collis, K. F. (1982). Evaluation the quality of learning: the SOLO taxonomy (structure of the observed learning outcome). Academic Press.

[10] Ackoff, R. L. (1989). From data to wisdom. Journal of applied systems analysis, 16(1), 39.

[11] Zimmermann, H. (1980). OSI reference model--The ISO model of architecture for open systems interconnection. IEEE Transactions on communications, 28(4), 425-432. https://doi.org/10.1109/TCOM.1980.1094702

[12] Forouzan, B. A. (2002). TCP/IP protocol suite. McGraw-Hill, Inc..

[13] Wang, Y., Wang, Y., Patel, S., \& Patel, D. (2006). A layered reference model of the brain (LRMB). IEEE Transactions on Systems, Man, and Cybernetics, Part C (Applications and Reviews), 36(2), 124-133. https://doi.org/10.1109/TSMCC.2006.871126

[14] Rowley, J. (2007). The wisdom hierarchy: representations of the DIKW hierarchy. Journal of information science, 33(2), 163-180. https://doi.org/10.1177/0165551506070706

[15] Flavell, J. H. (1992). Cognitive development: Past, present, and future. Developmental psychology, 28(6), 998. https://doi.org/10.1037/0012-1649.28.6.998

[16] Forehand, M. (2010). Bloom's taxonomy. Emerging perspectives on learning, teaching, and technology, $41,47$.

[17] Harvey, B. M. (2016). Quantity Cognition: Numbers, Numerosity, Zero and Mathematics. Current Biology, 26(10), R419-R421. https://doi.org/10.1016/j.cub.2016.03.059

[18] Baddeley, A. D. (1986). Working memory. Oxford, UK: Oxford University Press.

[19] Toll, S. W., Kroesbergen, E. H., \& Van Luit, J. E. (2016). Visual working memory and number sense: Testing the double deficit hypothesis in mathematics. British Journal of Educational Psychology, 86(3), 429-445. https://doi.org/10.1111/bjep.12116

[20] Swanson, H. L., \& Fung, W. (2016). Working memory components and problem-solving accuracy: Are there multiple pathways?. Journal of Educational Psychology, 108(8), 1153. https://doi.org/10.1037/edu0000116

[21] Christakou, A., Murphy, C. M., Chantiluke, K., Cubillo, A. I., Smith, A. B., Giampietro, V., ... \& Rubia, K. (2013). Disorder-specific functional abnormalities during sustained attention in youth with attention deficit hyperactivity disorder (ADHD) and with autism. Molecular psychiatry, 18(2), 236-244. https://doi.org/10.1038/mp.2011.185

[22] Anobile, G., Stievano, P., \& Burr, D. C. (2013). Visual sustained attention and numerosity sensitivity correlate with math achievement in children. Journal of experimental child psychology, 116(2), 380-391. https://doi.org/10.1016/j.jecp.2013.06.006

[23] Dormal, V., Schuller, A. M., Nihoul, J., Pesenti, M., \& Andres, M. (2014). Causal role of spatial attention in arithmetic problem solving: evidence from left unilateral neglect. $\mathrm{Neu}$ ropsychologia, 60, 1-9. https://doi.org/10.1016/j.neuropsychologia.2014.05.007

[24] Korhonen, J., Nyroos, M., Jonsson, B., \& Eklöf, H. (2017). Additive and multiplicative effects of working memory and test anxiety on mathematics performance in grade 3 students. Educational Psychology, 1-24. 
[25] Owens, M., Stevenson, J., Hadwin, J. A., \& Norgate, R. (2014). When does anxiety help or hinder cognitive test performance? The role of working memory capacity. British Journal of Psychology, 105(1), 92-101. https://doi.org/10.1111/bjop.12009

[26] Fischer, M. H., \& Fias, M. H. (2005). Spatial representation of numbers. Handbook of mathematical cognition, 43.

[27] Phillipson, S. N., \& Callingham, R. (2009). Understanding mathematical giftedness: Integrating self, action repertoires and the environment. In International handbook on giftedness (pp. 671-698). Springer Netherlands. https://doi.org/10.1007/978-1-4020-6162-2 33

[28] Duffy, G., Sorby, S., Nozaki, S., \& Bowe, B. (2016, October). Exploring the role of spatial cognition in problem solving. In Frontiers in Education Conference (FIE), 2016 IEEE (pp. 1-4). IEEE.

[29] Cheng, Y. L., \& Mix, K. S. (2014). Spatial training improves children's mathematics ability. Journal of Cognition and Development, 15(1), 2-11. https://doi.org/10.1080/152483 72.2012.725186

[30] Passolunghi, M. C., Vercelloni, B., \& Schadee, H. (2007). The precursors of mathematics learning: Working memory, phonological ability and numerical competence. Cognitive Development, 22(2), 165-184. https://doi.org/10.1016/j.cogdev.2006.09.001

[31] Krajewski, K., \& Schneider, W. (2009). Exploring the impact of phonological awareness, visual-spatial working memory, and preschool quantity-number competencies on mathematics achievement in elementary school: Findings from a 3-year longitudinal study. Journal of experimental child psychology, 103(4), 516-531. https://doi.org/10.1016/j.jecp.2009. 03.009

[32] Diamond, A. (2013). Executive functions. Annual review of psychology, 64, 135-168. https://doi.org/10.1146/annurev-psych-113011-143750

[33] Cragg, L., \& Gilmore, C. (2014). Skills underlying mathematics: The role of executive function in the development of mathematics proficiency. Trends in Neuroscience and Education, 3(2), 63-68. https://doi.org/10.1016/j.tine.2013.12.001

[34] Bull, R., \& Scerif, G. (2001). Executive functioning as a predictor of children's mathematics ability: Inhibition, switching, and working memory. Developmental neuropsychology, 19(3), 273-293. https://doi.org/10.1207/S15326942DN1903 3

[35] Verdine, B. N., Irwin, C. M., Golinkoff, R. M., \& Hirsh-Pasek, K. (2014). Contributions of executive function and spatial skills to preschool mathematics achievement. Journal of Experimental Child Psychology, 126, 37-51. https://doi.org/10.1016/j.jecp.2014.02.012

[36] Diamond, A., \& Taylor, C. (1996). Development of an aspect of executive control: Development of the abilities to remember what I said and to "Do as I say, not as I do". Developmental psychobiology, 29(4), 315-334. https://doi.org/10.1002/(SICI)1098-2302(199605) 29:4<315::AID-DEV2>3.0.CO;2-T

[37] Jacques, S., \& Zelazo, P. D. (2001). The Flexible Item Selection Task (FIST): A measure of executive function in preschoolers. Developmental neuropsychology, 20(3), 573-591. https://doi.org/10.1207/S15326942DN2003 2

[38] Fuchs, L. S., Fuchs, D., Stuebing, K., Fletcher, J. M., Hamlett, C. L., \& Lambert, W. (2008). Problem solving and computational skill: Are they shared or distinct aspects of mathematical cognition?. Journal of educational psychology, 100(1), 30. https://doi.org/10.1037/0022-0663.100.1.30

[39] Schneider, W., \& Artelt, C. (2010). Metacognition and mathematics education. ZDM, 42(2), 149-161. https://doi.org/10.1007/s11858-010-0240-2

[40] Tobias, S. \& Everson, H. T. (2009). The importance of knowing what you know: A knowledge monitoring framework for studying metacognition in education. Handbook of metacognition in education, 107-127. 
[41] Drigas, A. S., \& Pappas, M. A. (2017). The Consciousness-Intelligence-Knowledge Pyramid: An 8x8 Layer Model. International Journal of Recent Contributions from Engineering, Science \& IT (iJES), 5(3), 14-25. https://doi.org/10.3991/ijes.v5i3.7680

[42] Özsoy, G. (2011). An investigation of the relationship between metacognition and mathematics achievement. Asia Pacific Education Review, 12(2), 227-235. https://doi.org/10.1007/s12564-010-9129-6

[43] Carr, M., Alexander, J., \& Folds-Bennett, T. (1994). Metacognition and mathematics strategy use. Applied Cognitive Psychology, 8(6), 583-595. https://doi.org/10.1002/acp.23 $\underline{50080605}$

[44] Pennequin, V., Sorel, O., Nanty, I., \& Fontaine, R. (2010). Metacognition and low achievement in mathematics: The effect of training in the use of metacognitive skills to solve mathematical word problems. Thinking \& Reasoning, 16(3), 198-220. https://doi.org/10.1080/13546783.2010.509052

[45] Mevarech, Z., \& Fridkin, S. (2006). The effects of IMPROVE on mathematical knowledge, mathematical reasoning and meta-cognition. Metacognition and learning, 1(1), 85-97. https://doi.org/10.1007/s11409-006-6584-x

[46] Geary, D. C. (2000). From infancy to adulthood: The development of numerical abilities. European child \& adolescent psychiatry, 9, S11-S16. https://doi.org/10.1007/s00787 0070004

[47] LeFevre, J. A. (1990). Strategic and nonstrategic processing in the development of mathematical cognition. Children's strategies: Contemporary views of cognitive development, 213.

[48] Henningsen, M., \& Stein, M. K. (1997). Mathematical tasks and student cognition: Classroom-based factors that support and inhibit high-level mathematical thinking and reasoning. Journal for research in mathematics education, 524-549. https://doi.org/10.2307/ $\underline{749690}$

[49] LeFevre, J. A., Skwarchuk, S. L., Smith-Chant, B. L., Fast, L., Kamawar, D., \& Bisanz, J. (2009). Home numeracy experiences and children's math performance in the early school years. Canadian Journal of Behavioural Science/Revue canadienne des sciences du comportement, 41(2), 55. https://doi.org/10.1037/a0014532

[50] Jordan, N. C., Glutting, J., \& Ramineni, C. (2010). The importance of number sense to mathematics achievement in first and third grades. Learning and individual differences, 20(2), 82-88. https://doi.org/10.1016/j.lindif.2009.07.004

[51] Izard, V., Sann, C., Spelke, E. S., \& Streri, A. (2009). Newborn infants perceive abstract numbers. Proceedings of the National Academy of Sciences, 106(25), 10382-10385. https://doi.org/10.1073/pnas.0812142106

[52] Hyde, D. C., Berteletti, I., \& Mou, Y. (2016). Approximate numerical abilities and mathematics: Insight from correlational and experimental training studies. Progress in brain research, 227, 335-351. https://doi.org/10.1016/bs.pbr.2016.04.011

[53] Hyde, D. C., Berteletti, I., \& Mou, Y. (2016). Approximate numerical abilities and mathematics: Insight from correlational and experimental training studies. Progress in brain research, 227, 335-351. https://doi.org/10.1016/bs.pbr.2016.04.011

[54] Fuchs, L. S., Geary, D. C., Compton, D. L., Fuchs, D., Schatschneider, C., Hamlett, C. L., ... \& Bryant, J. D. (2013). Effects of first-grade number knowledge tutoring with contrasting forms of practice. Journal of Educational Psychology, 105(1), 58. https://doi.org/10.1037/a0030127

[55] Lenat, D. B., \& Durlach, P. J. (2014). Reinforcing math knowledge by immersing students in a simulated learning-by-teaching experience. International Journal of Artificial Intelligence in Education, 24(3), 216-250. https://doi.org/10.1007/s40593-014-0016-x 
[56] Posamentier, A. S., \& Krulik, S. (2008). Problem-solving strategies for efficient and elegant solutions, grades 6-12: a resource for the mathematics teacher. Corwin press.

[57] Hoffman, B. (2010). "I think I can, but I'm afraid to try": The role of self-efficacy beliefs and mathematics anxiety in mathematics problem-solving efficiency. Learning and Individual Differences, 20(3), 276-283. https://doi.org/10.1016/j.lindif.2010.02.001

[58] Muis, K. R. (2008). Epistemic profiles and self-regulated learning: Examining relations in the context of mathematics problem solving. Contemporary Educational Psychology, 33(2), 177-208. https://doi.org/10.1016/j.cedpsych.2006.10.012

[59] Wilkerson, M., \& Wilensky, U. (2008). How Do Mathematicians Learn Mathematics?. Proceedings of PME 32 and PME-NA 30, 4, 409-416.

[60] Greer, B. (2009). Representational flexibility and mathematical expertise. ZDM, 41(5), 697-702. https://doi.org/10.1007/s11858-009-0211-7

[61] Scott, W. A. (1962). Cognitive complexity and cognitive flexibility. Sociometry, 405-414. https://doi.org/10.2307/2785779

[62] Schoenfeld, A. (2009). Learning to think mathematically: Problem solving, metacognition, and sense-making in mathematics. Colección Digital Eudoxus, (7).

[63] Zazkis, R., \& Liljedahk, P. (2002). Generalization of patterns: The tension between algebraic thinking and algebraic notation. Educational studies in mathematics, 49(3), 379-402. https://doi.org/10.1023/A:1020291317178

[64] Tsamir, P. (2007). When intuition beats logic: prospective teachers' awareness of their same sides-same angles solutions. Educational Studies in Mathematics, 65(3), 255-279. https://doi.org/10.1007/s10649-006-9053-1

[65] Sophian, C. (2017). The origins of mathematical knowledge in childhood. Routledge.

\section{Authors}

Marios A. Pappas is with National and Kapodistrian University of Athens, Greece.

Athanasios S. Drigas is with the National Center for Scientific Research 'Demokritos', Athens, Greece.

Fotini Polychroni is with National and Kapodistrian University of Athens, Greece.

Article submitted 27 March 2018. Resubmitted 12 June 2018. Final acceptance 13 July 2018. Final version published as submitted by the authors. 